\title{
Immuno-biochemical evaluations of phenol and thimerosal as antigen preservatives in Montenegro skin test
}

\author{
Wilson Mayrink ${ }^{a}$, George Luis Lins Machado Coelho ${ }^{b}$, Tânia Mara P.D. Guimarães ${ }^{c}$, \\ Hélida Monteiro de Andrade ${ }^{\mathrm{d}}$, Elúzia de Castro Peres ${ }^{\mathrm{c}}$, Carlos Alberto da Costa ${ }^{\mathrm{c}}$, \\ Vicente de Paulo Coelho Peixoto de Toledo ${ }^{\mathrm{c}, *}$ \\ ${ }^{a}$ Universidade Federal de Minas Gerais, Instituto de Ciências Biológicas, Depto de Parasitologia, Brazil \\ ${ }^{\mathrm{b}}$ Universidade Federal de Ouro Preto, Faculdade de Farmácia, Brazil \\ ${ }^{\mathrm{c}}$ Universidade Federal de Minas Gerais, Faculdade de Farmácia, Depto de Análises Clínicas e Toxicológicas, Brazil \\ d Universidade Federal do Piauí, Centro de Ciências da Saúde, Depto de Parasitologia, Brazil
}

Received 10 June 2005; received in revised form 27 January 2006; accepted 10 February 2006

Available online 9 March 2006

\begin{abstract}
Montenegro skin test (MST) represents the main complementary diagnostic test for tegumentary leishmaniases (TL) in endemic regions. Most antigen formulations used for the MST contain thimerosal as preservative. The Food and Drug Administration (FDA), however, recommended reducing or eliminating thimerosal from vaccines and other biological reagents and the Agência Nacional de Vigilância Sanitária (ANVISA) in Brazil, prohibited the use of mercurial compounds in immunobiologicals. In the search for an alternative stabilizer, phenol and thimerosal were tested as antigen preservatives in MST. Formulations were tested when fresh and after a 12 -month storage at $4{ }^{\circ} \mathrm{C}$ in TL confirmed mice and human patients, and were evaluated for protein constitution by SDS-PAGE, Western blot and anti-gp63 ELISA. In mice, a decrease in the diagnostic effectiveness in merthiolate formulation was observed after a 12-month storage. SDS-PAGE, Western blot and anti-gp63 ELISA analyses showed a degradation of antigen proteins in both formulations after 12-month storage and that phenol-preserved antigen was quantitatively and qualitatively better than the merthiolate-preserved one. In patients, the average of induration diameter was larger in fresh antigens $(p<0.05)$. However, storage time did not jeopardize their diagnostic capacity. No non-specific reactions produced by phenol or merthiolate were observed neither in humans nor in mice. Phenol could be a good alternative to replace the merthiolate in MST, and despite the proteolytic activity, antigens remain viable for at least 12 months.
\end{abstract}

(C) 2006 Elsevier B.V. All rights reserved.

Keywords: Cutaneous leishmaniasis; Montenegro skin test; Thimerosal; Phenol; Stability

\section{Introduction}

The leishmaniases are diseases with different clinical manifestations. They are caused by several species of the

\footnotetext{
* Corresponding author. Tel.: +55 3134996876 ; fax: +553134996876 .

E-mail address: toledovp.bh@terra.com.br (V.P.C.P. de Toledo).
}

genus Leishmania. The Leishmania is a protozoan transmitted through the bite of the female sandfly of the genera Phlebotomus or Lutzomyia. Leishmaniases are among the most important parasite diseases and are endemic in all continents, except Oceania, with a total of 350 million people at risk, affecting at least 12 million people worldwide (WHO, 2002). These numbers are probably underestimated as figures of 1-1.5 million new cases of tegumentar leishmaniasis (TL) and 500,000 new cases of 
visceral leishmaniasis (VL) a year have been mentioned (Desjeux, 1996). Tegumentar leishmaniasis constitutes an important problem for public health in Brazil with more than 30,000 cases reported yearly to Ministry of Health, Brazil.

The interdermoreaction carried out by Montenegro (1926) represents the main complementary exam for TL diagnosis in endemic areas, with sensitivity ranging from 86 to $100 \%$ and specificity around $100 \%$ (Guedes et al., 1990). It usually serves as an exposure indicator or as an immunity indicator, for instance, in a follow-up in vaccination programs and as a parameter to evaluate protection (da Costa et al., 1996).

Since 1930, thimerosal has been used as a preservative in a number of immunobiologicals, including vaccines and in the current formulation of Montenegro antigen (da Costa et al., 1996). However, a few years ago, Food and Drug Administration (FDA), considering neurotoxicity and other adverse effects of organomercurial compounds, determined the modernization of the process of production of immunobiologicals, which culminated in the recommendation of reduction in the use of thimerosal and its elimination from vaccines and other biological reagents. As a consequence of this measure, ANVISA, in Brazil prohibited the use of mercurial compounds in drugs and decided to maintain the use of mercurial derivatives as immunobiological preservatives, but in minimal concentrations suitable to each product (Brasil, 2001; FDA/CBER, 2005). There is also a possibility of non-specific response to thimerosal, resulting in falsepositive reactions (Marzochi et al., 1998; Paranhos-Silva et al., 2001).

The formulation for Montenegro antigen proposed in this study has been used in Minas Gerais (Brazil), a TL endemic area, since 1996 (da Costa et al., 1996). It is very important to obtain accurate data about its stability and quality in order to keep its industrial production possible, even when there are some changes in its formulation.

In this study, phenol was investigated as an alternative preservative for Montenegro test antigen.

\section{Materials and methods}

\subsection{Preparation of Montenegro antigen for intradermoreaction}

An antigen standardized by da Costa et al. (1996), composed of a sonicated suspension of Leishmania (Leishmania) amazonensis (IFLA/BR/67/PH8) promastigotes were diluted in a solution of thimerosal in saline at $1: 10,000(\mathrm{v} / \mathrm{v})$ or in a solution of phenol in saline at $0.35 \%(\mathrm{v} / \mathrm{v})$. Fresh antigens were used as well as anti- gens stored for 12 months at $4{ }^{\circ} \mathrm{C}$. The use of phenol as a preservative followed the guidance of technical specialists from Laboratório de Extratos Alergênicos (Rio de Janeiro, Brazil) who use it routinely at $0.35 \%$ for dilution and preservation of allergenic extracts utilized in intradermoreactions to diagnose hypersensitivity to different allergens.

\subsection{Mice infection}

Six to twelve-month-old female of C57BL/10 isogenic mice, maintained in colony at breeding facilities of Departamento de Parasitologia do Instituto de Ciências Biológicas da Universidade Federal de Minas Gerais (UFMG) were used. Two groups of 10 animals were infected subcutaneously with $0.1 \mathrm{ml}$ of a suspension containing $10^{5}$ promastigotes $/ \mathrm{ml}$ of $L$. L. amazonensis obtained from the skin culture of infected hamsters.

\subsection{Cellular immune response—foot pad swelling test}

After 42 days of infection, when lesions were established, each animal received the antigens previously described. Group I received phenol-preserved antigen and Group II received merthiolate-preserved antigen. All the procedure was repeated after 12-months of storage of the antigen with another groups of infected mice. MST was carried out by injecting a $50 \mu \mathrm{l}$-inoculum containing $20 \mu \mathrm{g}$ of the antigens in the foot pad of the right paws of infected mice, and the same volume of the solution of merthiolate in saline and/or phenol in saline was inoculated in the foot pad of the left paws (Perez et al., 1981). Swelling was measured 24 and $48 \mathrm{~h}$ after the inoculation with a micrometer (Mitutoyo 2046-08, USA). The measurement of the foot pad swelling test was performed, considering the mean difference between the right paw thickness (test) and that of the left paw thickness (control).

\subsection{Biochemical evaluation}

Twenty micrograms of antigen were submitted to electrophoresis in $10 \%$ polyacrilamide gel (SDS-PAGE) (Laemmli, 1970). Then, the gel was fixed overnight in $50 \%$ methanol and stained by the silver nitrate method (Merril et al., 1981).

\subsection{Western blot reaction}

In order to identify the persistence of the main antigens of the parasite in different antigen formula- 
tions (merthiolate and phenol), fresh and after 12-month of storage, Western blot (Towbin et al., 1979) was carried out employing a pool of sera from infected mice. Montenegro antigens were submitted to SDSPAGE (Laemmli, 1970), electrotransferred to nitrocellulose membrane $-0.45 \mu \mathrm{m}$ (SIGMA N-8392, USA), incubated with a pool of sera from infected mice (diluted at 1:100) and revealed with goat antibody to mouse IgG - peroxidase conjugate (SIGMA A9309, USA).

\subsection{Study of GP63 kDa stability}

Polystyrene microplates (Hemobag, Campinas, Brazil) were sensitized with $1 \mu \mathrm{g} /$ well of rabbit $\mathrm{IgG}$ specific to $L$. L. amazonensis. Fifty microgram of each Montenegro antigen were added. After incubation, anti-gp63 monoclonal antibody (36CG4C11 clone) was added. It was incubated with goat antibody to mouse IgG, peroxidase conjugate (SIGMA A9309, USA) and the reaction was revealed by adding hydrogen peroxide and $o$-phenylenediamine dihydrochloride. Absorbance was determined in an automatic ELISA reader at $492 \mathrm{~nm}$. A sample with gp63 kDa was considered preserved when the average absorbance was equal or higher than 0.500 (Guimarães et al., 1996).

\subsection{Antigen evaluation in TL patients}

A paired design was carried out with 84 TL patients diagnosed by parasitological exam. Each individual received two injections of $0.1 \mathrm{ml}$ of two antigenic preparations in two sites of the same forearm. All patients received an equal volume of phenol and merthiolate diluents as control for non-specific reactions on the other forearm. The readings were carried out 48 -h after antigen injection. The average between the two perpendicular diameters was calculated. Indurations $\geq 5 \mathrm{~mm}$ were recorded as positive for each antigen (Melo et al., 1977).
From this sampling, 35 patients received fresh antigens and 49 received antigens after 12-month storage at $4{ }^{\circ} \mathrm{C}$.

\subsection{Statistical analysis}

Data obtained form the antigen evaluation in TL patients and the foot pad swelling test were analyzed by one-way ANOVA. The difference between fresh and preserved antigen formulations assayed by gp-63 ELISA was analyzed utilizing paired $t$-test.

\section{Results}

Table 1 shows results of foot pad swelling test. Phenol-preserved antigen was found to induce the same delayed-type hypersensitivity (DTH) response regardless it was fresh or stored or the reading interval ( 24 or $48 \mathrm{~h}$ ). Regarding the merthiolate-preserved antigen after 1 year storage, DTH was lower when swelling reading was carried out after $48 \mathrm{~h}$ and significantly lower $(p<0.05)$ if compared to phenol-preserved antigen for a year. In none of these preparations, allergic reactions to the preservative were observed, as the readings of the paws inoculated only with diluent solutions have always been significantly lower $(p<0.05)$ than the readings of the paws inoculated with antigen.

Western blot tests were carried out with immobilized phenol- and merthiolate-preserved antigens, triggering a reaction against sera of experimentally infected mice. In fresh formulations, a larger number of antigenic bands were developed, as well as a better defined reaction to phenol-preserved antigen was obtained. Thus, representative bands for the main parasite antigens, such as those of gp46, gp63, 97 and $116 \mathrm{kDa}$, were identified. After a 1 year storage, it was not possible to evaluate the immunoreactivity of the preparations studied due to intense protein degradation of most antigenic components in both formulations (Fig. 1).

Table 1

Foot pad swelling test carried out in Leishmania infected mice, using fresh merthiolate and phenol-preserved antigens and those after 12-month storage

Time of antigen preparation

Skin test result (mm)

\begin{tabular}{|c|c|c|c|c|}
\hline & & & & \\
\hline & Antigen with merth & & Antigen with pheno & \\
\hline & $24 \mathrm{~h}($ mean \pm s.d. $)$ & $48 \mathrm{~h}($ mean \pm s.d. $)$ & $24 \mathrm{~h}($ mean \pm s.d. $)$ & $48 \mathrm{~h}($ mean \pm s.d. $)$ \\
\hline Fresh & $0.908 \pm 0.409$ & $0.757 \pm 0.493$ & $0.996 \pm 0.606$ & $1.067 \pm 0.2634$ \\
\hline After 12 months & $0.519 \pm 0.3081$ & $0.389 \pm 0.227^{*}$ & $0.703 \pm 0.3645$ & $0.911 \pm 0.3865$ \\
\hline
\end{tabular}

The data represent the average differences between right paw swelling (test) and left paw swelling (control) for each group. s.d., standard deviation.

* Significant differences $(p<0.05)$ for the same preservative and time of reading after 12 months. 


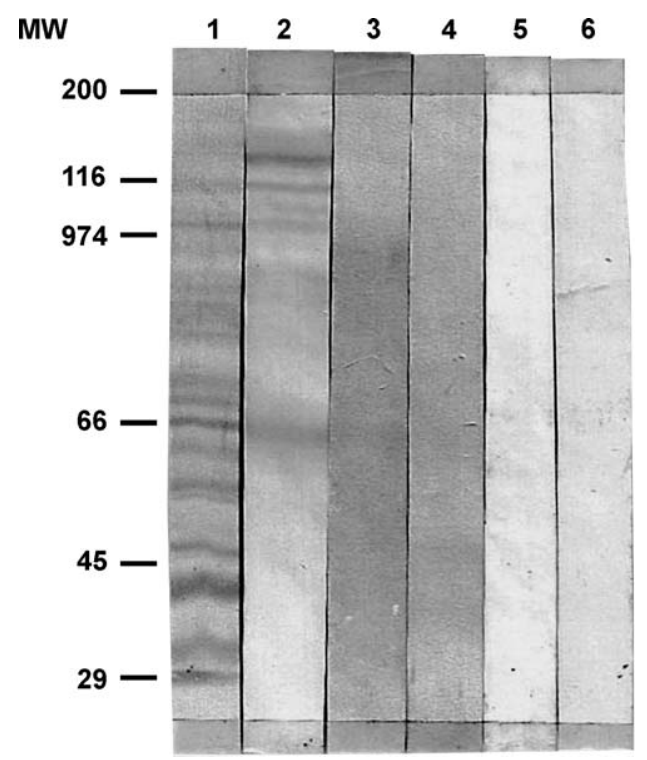

Fig. 1. Western blot employing fresh phenol-preserved antigens (tracks 1, 3 and 5) and fresh merthiolate-preserved antigens (tracks 2, 4 and 6) carried out employing a pool of sera from infected mice (tracks 1-4) and a pool of sera from normal mice (tracks 5 and 6). MW, molecular weight markers $(\mathrm{kDa})$.

In Fig. 2, qualitative and quantitative differences were observed in the total proteins profile between the two fresh samples. So, the electrophoresis of phenolpreserved antigen revealed a number of proteins, including those already described in the literature, as immunogenically more important: gp63, gp46 and $30 \mathrm{kDa}$, among others (Nascimento et al., 1990). However, antigenic bands were not observed in Western blots of both phenol- and merthiolate-preserved antigens stored for 1 year. Fig. 3 shows observations on gp63 stability analysis. This glycoprotein was present and preserved in both antigen formulations (phenol and merthiolate) as observed in its interaction with 36CG4C11 monoclonal antibody which is specific, showing that one of the main immunogens of Montenegro antigen is reactive in both fresh formulations in similar levels to that of the fresh L. L. amazonensis whole extract. After 1 year storage, however, a significant decrease $(p<0.05)$ was observed in the optical density in both antigen preparations.

Comparisons between fresh phenol- and merthiolatepreserved antigens and those stored for 12 months at $4{ }^{\circ} \mathrm{C}$, in subjects with a positive parasitological exam, showed that the mean induration diameters produced by the antigens preserved for 12 months were significantly lower than when the fresh antigens were used in both preservation processes (Table 2).

In subjects with positive parasitological exams, a concordance of $100 \%$ was observed in responses obtained

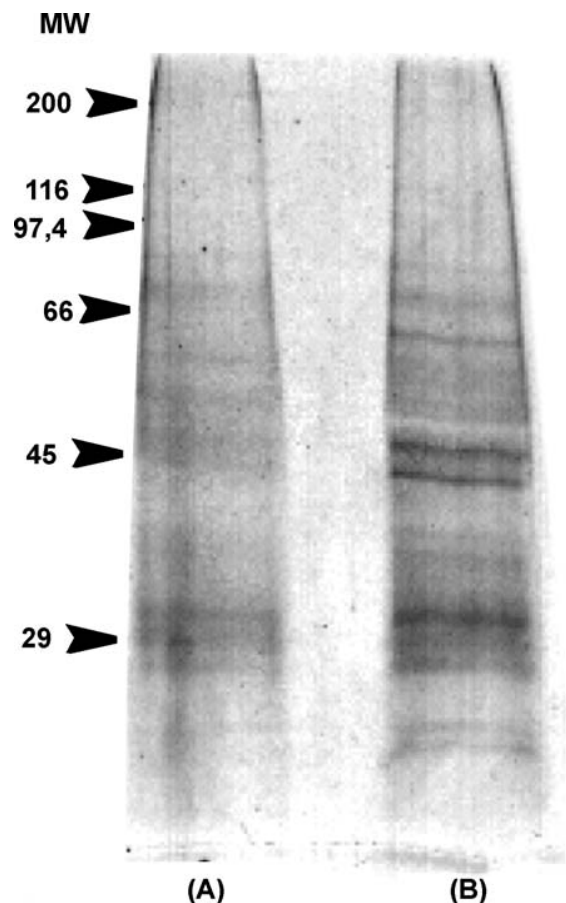

Fig. 2. Electrophoresis in $10 \%$ polyacrilamide gel silver stained, using fresh formulations. MW, molecular weight markers $(\mathrm{kDa})$. Lane A, protein profile for merthiolate-preserved antigens. Lane B, protein profile for phenol-preserved antigens.

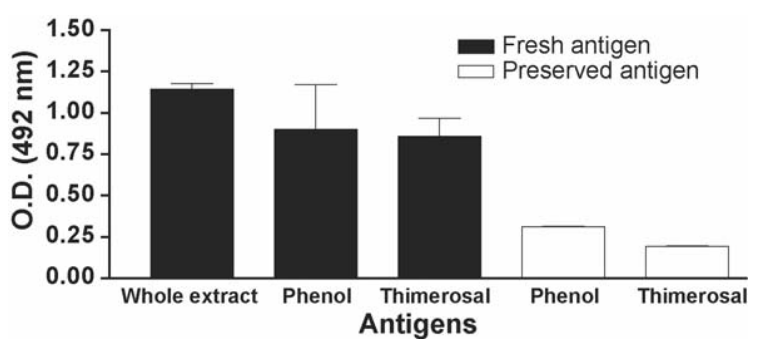

Fig. 3. Immunoenzymatic reaction (ELISA) to detect Leishmania gp63 in fresh merthiolate and phenol-preserved antigens as well as in those stored for 12 months at $4{ }^{\circ} \mathrm{C}$.

Table 2

Montenegro test in patients with TL using fresh merthiolate and phenol antigens and those with a 12-month storage

\begin{tabular}{lll}
\hline Preparation time & \multicolumn{2}{l}{ Induration $(\mathrm{mm})(\mathrm{mean} \pm$ s.d. $)$} \\
\cline { 2 - 3 } & Merthiolate & Phenol \\
\hline Fresh $(n=35)$ & $20.79 \pm 12.47$ & $20.41 \pm 12.69$ \\
After 12 months $(n=49)$ & $12.13 \pm 7.32^{*}$ & $14.82 \pm 10.15^{*}$ \\
\hline
\end{tabular}

\footnotetext{
* Significant differences $(p<0.05)$ for the same preservative after 12
} months. 
with both antigens (merthiolate and phenol) fresh or preserved in TL patients. No non-specific reactions were observed with the diluents used.

\section{Discussion}

Although the intradermal test has been originally developed for human use, some authors have shown that Montenegro intradermoreaction may be adapted for dogs (Marzochi and Barbosa-Santos, 1988; Hermeto et al., 1994; Paranhos-Silva et al., 2001). Thus, due to the universal use of the test, the quality of antigen preparation is essential, even in the absence of an international standardized preparation not only as for the antigen constitution, but also as for its biochemical and immunological features.

Considering FDA Modernization Act-FDMA (1997), FDA conducted a comprehensive review on the use of thimerosal in child vaccines, and as a precautionary measure, the Public Health Service (including National Institutes of Health, Center for Disease Control and Prevention and Health Resources and Services Administration) recommended that vaccine manufacturers should reduce or eliminate thimerosal in vaccines as soon as possible (CDC 1999/2000) and, in Brazil, ANVISA established that "all companies holding mercurial registrations that intend to maintain their trade mark should present a petition of change in the formula, substituting mercurials compounds and that direction and label texts should highlight the saying NEW FORMULA". The purpose of this study was to perform an immuno-biochemical evaluation of phenol and thimerosal as antigen preservatives in the MST. Montenegro antigen formulation proposed in this study has been used in the state of Minas Gerais (Brazil), an endemic area for TL, since 1996 (da Costa et al., 1996). Thus, it is very important to investigate accurate data concerning its stability and quality in order to make its industrial production possible even when its formulation is changed, starting by replacing thimerosal by phenol. This replacement followed rules and procedures by Laboratório de Extratos Alergênicos (Rio de Janeiro, Brazil), which routinely produces extracts for intradermal tests in the presence of phenol at $0.35 \%$ to check the hypersensitivity to different allergens.

Thimerosal is reported as a powerful inducer of delayed-type hypersensitivity (Imperato et al., 1974; Marzochi et al., 1998; Forstrom et al., 1980). Fagundes et al. (2003) also showed its capacity to trigger immediate allergic reactions. A high proportion of dogs showed some allergic reaction, fact that supports the idea of elim- inating thimerosal from the preparation to be used in dogs (Paranhos-Silva et al., 2001).

According to our results, phenol-preserved antigen has always induced a typical delayed-type hypersensitivity response in two moments of the study (fresh and after 1 year of storage), since no non-specific and/or allergic reactions were observed in any situation with the phenol concentrations used both in mice and in humans, contrasting with Pineda et al. (2001) who showed some false-positive results for leishmanin skin test due to phenol-containing diluent. Phenol innocuousness has already been reported by other authors who observed that these reactions are so rare that the parallel administration of the antigen diluent as control is totally unnecessary (Aston and Thorley, 1970), unlike thimerosal that, among other clinical manifestations, has a neurotoxic potential (Mahaffey, 1999).

Regarding the stability of antigen formulation, both phenol and merthiolate effectively prevent from bacterial contamination but none of them stabilize proteins and polysaccharides (Weigle et al., 1991). However, stable antigens were observed for a long time in the presence of thimerosal. Antigen stability was reported for intradermal test from 4 to 10 years (Mayrink et al., 1978; Badaró et al., 1990; Alimohammadian et al., 1993). Nevertheless, it is worth highlighting that characteristics inherent to patients may determine the antigen sensitivity and potency. Features such as kind of injury (muco-cutaneous or cutaneous), injury duration (active or healed) and healing time affect Montenegro test sensitivity (Shaw and Lainson, 1976; Llanos-Cuentas et al., 1984; Jones et al., 1987; Saravia et al., 1989). Patients who had positive parasitological exams for cutaneous leishmaniasis and with injuries from 3 to 8 months, characteristics which are compatible to the use of intradermal test as diagnostic tool, took part in our study. Thus, after 1 year of preparation, even with a significant decrease in the mean induration diameter, all patients were still diagnosed through intradermal test. Although it was not significant, a tendency for diameter decrease in merthiolate preparation reactions after 1 year was observed. Regarding phenol preparation, in mice, a better reactogenicity of this preparation was observed, supported by a larger number of whole peptides revealed in polyacrilamide gel and also by the larger quantity of an important immunogen, gp63 kDa, a glycoproteins which accounts for the induction of most cellular immunity against the parasite (Nascimento et al., 1990; Russo et al., 1991).

In this study, the phenol-preserved fresh antigen was verified utilizing Western blot and presented a larger number of better-defined bands, supporting the idea of a higher effectiveness to preserve antigen epitopes. 
Besides, apparently, did not interfere with the immunoreactivity of the main antigens present in this formulation.

The use of phenol as preservative may be an appropriate alternative to replace organomercurial compounds, mainly because of its innocuousness, as phenol did not interfere with immunogenic properties of Montenegro antigen, and in a certain way, preserved protein components of this formulation more effectively for a short term.

\section{Acknowledgement}

We express our gratitude to Mr. Jair Cecílio de Paula for his valuable help and co-operation in the study area at Ambulatório de Leishmanioses de Caratinga, Minas Gerais, Brazil.

\section{References}

Alimohammadian, M.H., Kivanjah, M., Pak, F., Gaznavia, A., Kharazmi, A., 1993. Evaluation of the efficacy of Iran leishmanin and comparison with leishmanins from Wellcome (UK) and Roma (Italy) in cured cutaneous leishmaniasis patients. Trans. R. Soc. Trop. Med. Hyg. 87, 550-551.

Aston, D.L., Thorley, A.P., 1970. Leishmaniasis in Central Brazil: results of a Montenegro skin test survey among ameridians in the Xingu National Park. Trans. R. Soc. Trop. Med. Hyg. 64, 671-678.

Badaró, R., Pedral-Sampaio, D., Johnson, W.D., Reed, S.G., 1990. Evaluation of the stability of a soluble intradermal skin test antigen preparation in American visceral leishmaniasis. Trans. R. Soc. Trop. Med. Hyg. 84, 226-227.

Brasil, 2001. Agência Nacional de Vigilância Sanitária. Portaria n. 724 de 18 abr. 2001. Aprova Resolução RE n. 528, de 17/04/2001, que proíbe o uso de composto mercuriais nos medicamentos e dá outras providências. Diário Oficial da República Federativa do Brasil, Brasília, DF, 18 abr.

da Costa, C.A., Toledo, V.P.C.P., Genaro, O., Williams, P., Mayrink, W., 1996. Montenegro skin test-evaluation of the composition and stability of the antigen preparation. Mem. Inst. Oswaldo Cruz 91, 193-194.

Desjeux, P., 1996. Leishmaniasis: public health aspects and control. Clin. Dermatol. 14, 417-423.

Fagundes, A., Marzochi, K.B., Marzochi, M.C., 2003. Immediate and generalized reaction to Montenegro skin test. Rev. Soc. Bras. Med. Trop. 36, 413-414.

Forstrom, L., Hannuksela, M., Kousa, M., Lehmuskallio, E., 1980. Merthiolate hypersensitivity and vaccination. Contact Derm. 6, 241-245.

Guedes, A.C.M., Cucé, L.C., Furtado, T., 1990. Avaliação imunológica e histopatológica da Reação de Montenegro. An. Bras. Dermatol. $65,34 \mathrm{~S}-40 \mathrm{~S}$.

Guimarães, T.M.P.D., Toledo, V.P.C.P., da Costa, C.A., Costa, R.T., Genaro, O., Williams, P., Mayrink, W., 1996. Assessment of immunity induced in mice by glycoproteins derived from different strains and species of Leishmania. Mem. Inst. Oswaldo Cruz 91, 63-70.

Hermeto, M.V., Vieira-Dias, D., Genaro, O., Costa, C.A., Toledo, V.P.C.P., Michalick, M.S., Tafuri, W.L., Chaves, K.M., Mayrink, W., 1994. Outbreak of cutaneous leishmaniasis in the Rio Doce
Valley, Minas Gerais, Brazil. Mem. Inst. Oswaldo Cruz 84, 519521.

Imperato, P.J., Fofana, B., Sow, O., Diallo, S., 1974. Leishmanin skin sensitivity in the inland delta of the Niger. Trop. Geogr. Med. 26, 303-306.

Jones, T.C., Johnson Jr., W.D., Barreto, A., Lago, E., Badaro, R., Cerf, B., Reed, S.G., Netto, E.M., Tada, M.S., Franca, F., Wiese, K., Golighty, L., Fikrig, E., Costa, K.M.L., Cuba, C.C., Marsden, P.D., 1987. Epidemiology of American cutaneous leishmaniasis due to Leishmaniasis braziliensis braziliensis. J. Infect. Dis. 156, 73-83.

Laemmli, U.K., 1970. Cleavage of structural proteins during the assembly of the head of bacteriophage T4. Nature 27, 680-685.

Llanos-Cuentas, E.A., Marsden, P.D., Lago, E.L., Barreto, A.C., Cuba, C.C., Jhonson, W.D., 1984. Human mucocutaneous leishmaniasis in Tres Braços, Bahia - Brazil, an area of Leishmania braziliensis braziliensis transmission. II Cutaneous disease: presentation and evolution. Rev. Soc. Bras. Med. Trop. 17, 169-177.

Mahaffey, K.R., 1999. Methylmercury: a new look at the risks. Public Health Rep. 114, 402-413.

Marzochi, M.C.A., Barbosa-Santos, E.G.O., 1988. Evaluation of a skin test on the canine mucocutaneous leishmaniasis diagnosis. Mem. Inst. Oswaldo Cruz 83, 391-392.

Marzochi, K.B., Marzochi, M.A., Silva, A.F., Grativol, N., Duarte, R., Confort, E.M., Modabber, F., 1998. Phase I study of an inactivated vaccine against American Tegumentary leishmaniasis in normal volunteers in Brazil. Mem. Inst. Oswaldo Cruz 93, 205212.

Mayrink, W., Magalhães, P.A., Dias, M., da Costa, C.A., Melo, M.N., Oliveira-Lima, A., 1978. Response to Montenegro antigen after immunization with killed Leishmania promastigotes. Trans. R. Soc. Trop. Med. Hyg. 72, 676.

Melo, M.N., Mayrink, W., da Costa, C.A., Magalhães, P.A., Dias, M., Coelho, M.V., Batista, S.M., 1977. Padronização do Antígeno de Montenegro. Ver Inst. Med. Trop. São Paulo 19, 161164.

Merril, C.R., Goldman, D., Sedman, S.A., Ebert, M.H., 1981. Ultrasensitive stain for proteins in polyacrilamide gels shows regional variation in cerebrospinal fluid proteins. Science 211, 1437-1438.

Montenegro, J., 1926. Cutaneous reaction in leishmaniasis. Arch. Derm. Syphilol. 13, 187-194.

Nascimento, E., Mayrink, W., da Costa, C.A., Michalick, M.S.M., Melo, M.N., Barros, G.C., Dias, M., Antunes, C.M.F., Lima, M.S., Taboada, D.C., Liu, T.Y., 1990. Vaccination of humans against cutaneous leishmaniasis: cellular and humoral immune responses. Infect. Immun. 58, 2198-2203.

Paranhos-Silva, M., Pontes-de-Carvalho, L.C., Oliveira, G.G.S., Nascimento, E.G., dos-Santos, L.C., 2001. Skin reactions to thimerosal and leishmania in dogs from a leishmaniasis endemic area: it is better to keep them apart. Mem. Inst. Oswaldo Cruz 96, 679-681.

Perez, H., Pocin, M., Malav, I., 1981. Nonspecific immunodepression and protective immunity in mice infected with Leishmania mexicana. Infect. Immun. 32, 415-419.

Pineda, J.A., Macias, J., Morillas, F., Fernandez-Ochoa, J., Cara, J., de la Rosa, R., Martin-Sanchez, J., Gonzalez, M., Garcia-Briones, E., Delagado, J., Lissen, E., 2001. False-positive results of leishmanin skin test due to phenol containing diluent. Trans. R. Soc. Trop. Med. Hyg. 95, 173-174.

Russo, D.M., Burns, J.M., Carvalho, E.M., Armitage, R.J., Grabstein, K.H., Button, L.L., McMaster, W.R., Reed, S.G., 1991. Human $\mathrm{T}$ cell responses to gp63, a surface antigen of Leishmania. J. Immunol. 15, 3575-3580. 
Saravia, N.G., Valderrama, L., Labrada, M., Holguin, A.F., Navas, C., Palma, G., Weigle, K.A., 1989. The relationship of Leishmania braziliensis subspecies and immune response to disease expression in New World Leishmaniasis. J. Infect. Dis. 159, 725-735.

Shaw, J.J., Lainson, R., 1976. Leishmaniais in Brazil: some observations of intradermal reactions to different trypanosomatid antigens of patients suffering from cutaneous and muccocutaneous leishmaniasis. Am. J. Trop. Med. Hyg. 35, 79-85.

Towbin, H., Staehelin, T., Gordon, J., 1979. Electrophoretic transfer of proteins from polyacrylamide gels to nitrocellulose sheets: procedure and some applications. Proc. Natl. Acad. Sci. U.S.A. 76, 4350-4354.
U.S. Food and Drug Administration/Center for Biologics Evaluation and Research, 2005. The United States Code of Federal Regulations.Thimerosal in Vaccines. Washington DC. Disposable in: http://www.fda.gov/cber/vaccine/thimerosal.htm> (access on March 31, 2005).

Weigle, K.A., Valderrama, L., Arias, A.L., Santrich, C., Saravia, N.G., 1991. Leishmanin skin test standardization and evaluation of safety, dose, storage, longevity of reaction and sensitization. Am. J. Trop. Med. Hyg. 44, 260-271.

World Health Organization, 2002. Control of the leishmaniasis: report of a WHO expert comitee. World Health Organ. Tech. Rep. Ser., p. 793. 